\title{
Metabolic and glucostatic control of feeding
}

\author{
BY WOLFGANG LANGHANS \\ Institute for Animal Sciences, Swiss Federal Institute of Technology, Zurich, Switzerland
}

\section{Contrôle métabolique et glucostatique de l'alimentation}

\begin{abstract}
RÉSUMÉ
La preuve d'un contrôle métabolique de l'alimentation est tirée d'études qui montrent que l'administration parentérale aigüe et chronique de substrats énergétiques métaboliques diminue la prise d'aliments, alors que l'inhibition pharmacologique de l'ultilisation du glucose, ou l'oxydation des lipides stimule généralement l'alimentation. Comme la capacité du corps à stocker les glucides est limitée, l'utilisation du glucose prime sur l'oxydation des lipides après les repas et semble être plus importante pour la régulation à court terme de la prise de substrats énergétiques dans les espèces monogastriques. Les données disponibles aujourd'hui concordent avec l'idée que l'utilisation du glucose et des lipides est détectée par deux déctecteurs métaboliques de types probablement différents: (1) les détecteurs du glucose, situés dans le système nerveux central et à la périphérie (afférences vagales), et (2) les déctecteurs qui gèrent l'oxydation des lipides, très probablement situés dans le foie et connectés au cerveau principalement par des afférences vagales. Il est possible que l'activité de l'ATP et de la pompe à $\mathrm{Na}$ lie le métabolisme oxydatif du foie et le potentiel de membrane des déctecteurs, car la captation des phosphates dans le foie par le 2,5-anhydro-mannitol et l'inhibition de l'activité de la pompe à $\mathrm{Na}$ par l'ouabaïne est associé avec une stimulation de l'alimentation. Les hépatocytes peuvent également agir comme détecteurs pour l'oxydation des lipides, et peut-être d'autres substrats énergétiques dans le contrôle du métabolisme de l'alimentation. Le potentiel de membrane de l'hépatocyte est également influencé par des modifications dans le flux transmembranaire du potassium à travers des canaux membranaires spécifiques pour le $\mathrm{K}$, et dont l'ouverture dépend de l'augmentation du volume de l'hépatocyte. Ainsi, il est possible que les métabolites influencent le potentiel de membrane de l'hépatocyte indépendamment de leur oxydation. Bien qu'une fonction de déctecteur des hépatocytes dans le contrôle métabolique de l'alimentation apparaisse vraisemblable, il faut remarquer que cela n'a pas encore été prouvé, et qu'on ne sait pas clairement comment l'information métabolique est transmise des hépatocytes aux nerfs afférents. L'intégration de l'information des détecteurs pour l'utilisation du glucose et l'oxydation des lipides se produit essentiellement dans le système nerveux central. Pourtant, étant donné les multiples interactions entre l'utilisation des glucides et des lipides, une certaine intégration peut aussi se produire à la périphérie. Plusieurs résultats démontrent que la taille du dépôt de graisse influence l'alimentation. On suppose que cette interaction peut être de nature métabolique, mais le rôle et la nature exacts des signaux impliqués restent inconnus.
\end{abstract}

Because energy balance is mainly regulated through changes in food intake (e.g. Van Es et al. 1984; Katzeff \& Danforth, 1989), it is likely that some measure of energy in 
metabolism is involved in the control of feeding. This assumption is supported by numerous studies which show that parenteral administration of various fuels or pharmacological manipulation of fuel utilization affects feeding in man and animals. Often, the short-term reductions of food intake in response to acute administration of metabolites more than energetically compensated for the injected energy (see Langhans et al. 1985a; Tordoff \& Friedman, 1988). This supports the assumption that an acute increase in the rate of energy turnover is crucial for the short-term hypophagic effect of metabolic fuels (Langhans et al. 1985a). The food intake reduction in response to chronic administration of metabolic fuels or parenteral nutrition is proportional to the amount of energy provided by the infusion, but in this situation man and animals do not fully compensate for the administered energy. The food intake reduction is usually equivalent to about $40-70 \%$ of the infused energy (Woods et al. 1984; Walls \& Koopmans, 1989), depending on the timing of the infusion (Walls et al. 1991; Beverly et al. 1994a), and on the composition of the infusate (Walls \& Koopmans, 1989; Beverly et al. 1994a), with glucose and amino acids being generally more effective than lipids. In the rat, the energy content of infused fuels is optimally compensated (about $90 \%$ ) by a decrease in oral food intake when the pattern of infusion matches the diurnal pattern of food intake and when the nutrient composition of the infusate equals that of the diet (Beverly et al. 1994a). These and other findings (see Langhans \& Scharrer, 1992) suggest that parenterally administered substrates have to be oxidized to affect food intake. In line with this assumption, inhibitors of fuel utilization generally stimulate feeding (see Langhans \& Scharrer, 1992). All in all, most of the available data fit the hypothesis that feeding is inversely related to the rate of fuel utilization (Booth, 1972; Friedman \& Stricker, 1976; Nicolaidis \& Rowland, 1976; Langhans et al. 1985a). The present review will focus on the role of glucose and free fatty acids in the metabolic control of food intake because these substrates are the most important sources of energy in single-stomached species.

\section{THE ROLE OF GLUCOSE IN THE METABOLIC CONTROL OF FEEDING}

\section{Glucose utilization and feeding}

According to Mayer's (1953) glucostatic theory, an increase or decrease in glucose utilization can be sensed by cells with a special affinity for glucose and serves as a stimulus for satiety or hunger respectively. This hypothesis was based in part on the observation that carbohydrate reserves are proportionally depleted between meals to a greater extent than are reserves of protein or fat (Mayer, 1953). In concordance with the glucostatic theory, it has often been shown that cellular glucoprivation induced by glucose anti-metabolites like 2-deoxy-D-glucose (2-DG) or 5-thio-glucose (5-TG) stimulates feeding (glucoprivic feeding) in animals (Smith \& Epstein, 1969; Novin et al. 1973; Ritter \& Slusser, 1980) and man (Thompson \& Campbell, 1977). As 2-DG increases food intake by primarily increasing meal frequency (Larue-Achagiotis \& LeMagnen, 1981), glucose utilization seems to be involved in the maintenance of postprandial satiety.

In the rat, spontaneous (Louis-Sylvestre \& LeMagnen, 1980; Campfield et al. 1985) and scheduled (Müller et al. 1967) meals are preceded by a small (6-11\%) decline in blood glucose. A similar pre-meal decline in blood glucose has been reported recently in human subjects (Campfield et al. 1995). Intravenous glucose infusions which attenuated the pre-meal decline in blood glucose delayed the onset of the meal in the rat (Campfield et al. 1985). When food was withheld until blood glucose levels had returned to normal, 
meal onset was also delayed (Campfield et al. 1985). These results suggest that the pre-meal decline in blood glucose is causally related to meal onset. Unfortunately, it is unclear whether a change in glucose utilization accompanies the pre-meal decline in blood glucose because recordings of the RQ in relation to spontaneous meals yielded conflicting results (Nicolaidis, 1981; Even \& Nicolaidis, 1985). Indirect evidence for a causal relationship between decreases in blood glucose levels or glucose availability and hunger in man is also derived from studies in which meals with slow release carbohydrates were shown to produce a smaller but clearly longer sustained rise in blood glucose and a decrease in hunger ratings compared with meals containing potatoes (for example Leathwood \& Pollet, 1988; Torsdottir et al. 1989).

Blood glucose levels and glucose utilization in single-stomached species increase during and after carbohydrate-containing meals (for example Strubbe \& Steffens, 1977; Nicolaidis, 1981; Flatt et al. 1985; Surina et al. 1993). However, attempts to induce satiety by parenteral applications of glucose have not always been successful. Mayer (1953) and many others (for example Russek, 1970; Novin et al. 1974; Yin et al. 1979; Tordoff \& Friedman, 1986, 1988) observed an inhibition of feeding after parenteral administration of glucose, but some did not (for example Adair et al. 1968; Scharrer et al. 1974). Closer examination of the respective studies indicates that this discrepancy is due to different experimental conditions, such as the timing or route of glucose application, the composition of the test diet or the duration of the feeding test. Intravenous infusions of glucose plus amino acids in rats, given only during the period when the rats were fed, reduced food intake by about $70 \%$ of the infused energy (Walls et al. 1991). Novin et al. (1985) observed a potentiation of the satiety effect of parenterally-administered glucose by concomitant carbohydrate intake. This suggests that intravenous glucose infusions are more satiating at a time when concomitant oral food intake stimulates other satiety signals which interact with and strengthen the glucose effect. In some studies the satiating potency of glucose increased significantly when insulin was infused simultaneously (MacLagan, 1937; Nicolaidis \& Rowland, 1976; Even \& Nicolaidis, 1986). This provides indirect evidence for the role of glucose utilization in the satiety effect of parenterally-administered glucose and suggests that the glucoreceptors involved are at least partly sensitive to insulin. In summary, there is considerable evidence for a post-absorptive rnetabolic effect of glucose on feeding in addition to any effect that ingested glucose may have on the gastrointestinal tract. This raises the question of where glucose utilization is sensed.

\section{Glucosensors in the brain}

Mayer (1953) originally proposed that the glucostatic control of food intake is integrated into the homeostatic mechanisms of the brain which depend almost exclusively on glucose oxidation. Oomura (1976) and his group first provided electrophysiological evidence for the existence of two types of neurons that respond to glucose in the brain: the glucoreceptor neurons in the ventromedial hypothalamus, whose activity increases on systemic or direct electrophoretic application of glucose, and the so-called glucosesensitive neurons in the lateral hypothalamus, which are hyperpolarized and show suppressed activity with administration of glucose. An involvement of central glucosesensitive neurons in hunger is suggested by findings of a reliable increase in food intake in response to intracerebroventricular infusion of 2-DG (Miselis \& Epstein, 1975; Berthoud 
\& Mogenson, 1977) or 5-TG (Ritter \& Slusser, 1980) in rats. Attempts to elicit feeding in rats with intrahypothalamic 2-DG applications generally failed (Miselis \& Epstein, 1975; Berthoud \& Mogenson, 1977), indicating that local glucoprivation in the hypothalamus is not sufficient to initiate feeding. Instead, glucoprivic feeding seems to require glucosesensitive neurons in the area postrema-nucleus of the solitari tract (AP-NST) region of the hindbrain. When the aqueduct between the third and fourth ventricle was obstructed, microinjections of 5-TG into the fourth ventricle stimulated feeding in rats, whereas equivalent injections into the lateral ventricle did not (Ritter et al. 1981). Moreover, the feeding response to intracerebroventricular and systemic glucoprivation was impaired by administration of low doses of alloxan into the fourth ventricle (Murnane \& Ritter, 1985). Alloxan is a toxin that selectively destroys glucose-sensitive cells. These findings indicate that glucosensors in the hindbrain are also involved in the hyperphagic effect of peripheral glucoprivation. In line with this assumption, intravenously infused 2-DG induced Fos-like immunoreactivity in the AP-NST region of the rat (Ritter \& Dinh, 1994), and feeding induced by intraperitoneal 2-DG was abolished by lesions of the AP-NST, but not by subdiaphragmatic vagotomy (Ritter \& Taylor, 1990) or capsaicin pretreatment (Ritter \& Taylor, 1989). The latter findings also suggest that feeding in response to systemic $2-D G$ is normally not mediated by sensory afferents of the abdominal vagus.

Glucose given intracerebroventricularly decreased food intake, at least in some studies (for example Davies et al. 1981). Furthermore, a decrease in circulating glucose is associated with a decrease in $\alpha_{2}$-adrenergic-receptor binding and a concomitant increase in norepinephrine (NE) turnover in the hypothalamus, in particular in the paraventricular nucleus (PVN; see Leibowitz, 1988). This is interesting because central injection studies demonstrate a potent stimulatory effect of NE on feeding, which is mediated by $\alpha_{2}$-adrenergic receptors located in the hypothalamic PVN (see Leibowitz, 1988). Thus, an increase in hypothalamic paraventricular noradrenergic activity could well contribute to the effect of the previously mentioned pre-meal decline in blood glucose on meal initiation (Louis-Sylvestre \& LeMagnen, 1980; Campfield et al. 1985). Several lines of evidence indicate that in addition to NE, $\gamma$-aminobutyric acid and neuropeptide $\mathrm{Y}$ are essential neurochemicals in a hypothalamic system that stimulates feeding, in particular at the onset of the active cycle. This system is influenced by circulating cortisol and stimulates in particular carbohydrate intake (Leibowitz, 1988, 1992). In addition to causing changes in paraventricular NE turnover, slight and transient changes in blood glucose levels have also been shown to affect the spike frequency of cells in the lateral hypothalamic area (Himmi et al. 1988). The majority of responsive cells displayed either an activation during hypoglycaemia or a depression during hyperglycaemia (Himmi et al. 1988), which is a characteristic of the lateral-hypothalamic glucose-sensitive cells identified by Oomura (1976).

\section{Glucosensors in the liver}

It seems plausible that the liver is involved in the metabolic control of feeding because of its key role in metabolism and because it is exposed to the nutrient flow from absorption. Russek (1963) was the first to suggest that hepatic glucosensors are involved in the control of feeding. He reported that intraportal but not intrajugular infusion of glucose suppressed food intake in dogs fasted for $22 \mathrm{~h}$ (Russek, 1970). Although attempts to 
replicate these original findings and to extend them to other species yielded conflicting results (a decrease in food intake: for example Novin et al. 1974, 1985; Yin et al. 1979; no effect on food intake: for example Bellinger et al. 1976; Strubbe \& Steffens, 1977; an increase in food intake: Geiselman, 1984), systematic tests of portal glucose infusions by Tordoff \& Friedman $(1986,1988)$ and Tordoff et al. (1989) convincingly demonstrated that glucose infusions which produce metabolic changes within the physiological range and do not affect systemic blood glucose levels reduce food intake. Food intake was reduced by the same amount irrespective of the concentration of the glucose solution and the amount of glucose infused intraportally (Tordoff et al. 1989). Therefore, the critical metabolic event in the liver that influences food intake seems to be only indirectly coupled to portal glucose levels (Tordoff et al. 1989). Other aspects of the glucose supply like the portal-arterial glucose gradient (Tordoff et al. 1989) or the rate of glucose delivery into the portal vein (Novin et al. 1991) may be crucial. While food intake seems to be reduced when glucose is delivered at rates that match the physiological norm (Tordoff et al. 1989), meal size, meal duration and cumulative food intake seem to be increased when glucose or other hexoses are delivered at a higher rate (Geiselman, 1984; Novin et al. 1991). In addition to causing an increase in portal-vein-blood glucose, feeding stimulates a transient hepatic glycogenolysis in rats deprived of food for $12 \mathrm{~h}$ and ad lib.-fed rats (Langhans et al. 1982, 1984). Whether this meal-related hepatic glycogenolysis and concomitant glucose release is somehow involved in satiation or satiety remains an open question.

Studies with 2-DG also provide some evidence for an hepatic gluco-sensitive mechanism in the control of feeding. Infusion of 2-DG into the hepatic portal vein in rabbits caused a more rapid and greater increase in food intake than infusion into the jugular vein, and the effect was reduced by complete subdiaphragmatic vagotomy (Novin et al. 1973). In rats, both intrajugular and intraportal infusions of 2-DG produced a similar increase in food intake (Russel \& Mogenson, 1975), and hepatic branch vagotomy did not reduce the stimulatory effect of 2-DG on feeding in rats during the day (Tordoff et al. 1982). Delprete \& Scharrer $(1990,1994)$ confirmed this finding but, in addition, observed that the feeding response to $2-D G$ was reduced by hepatic branch vagotomy under some conditions, for instance when 2-DG was injected in the early dark phase of the lighting cycle and especially after consumption of a test meal. The finding that the disruption of postprandial satiety by $2-\mathrm{DG}$ is partially dependent on an intact hepatic branch of the vagus supports the hypothesis that glucose utilization by hepatic glucosensors contributes to the maintenance of postprandial satiety. It is also interesting that complete subdiaphragmatic as well as hepatic branch vagotomy disrupted the otherwise reliable coupling between the pre-meal decline in blood glucose levels and meal initiation in the rat. Whereas the transient pre-meal declines in blood glucose in both vagotomized groups were quantitatively similar to those observed in intact rats, they predicted meal initiation in only $55 \%$ of all trials compared with the $100 \%$ coupling of these events in intact rats (Campfield \& Smith, 1990). These findings are consistent with the idea that hepatic glucosensors play a role in the detection of the transient pre-meal decline in blood glucose and the reliable translation of this decline into meal initiation (Campfield \& Smith, 1990).

What is the morphological substrate of the hepatic sensors for glucose? Russek (Russek \& Grinstein, 1974; Russek, 1981) assumed that hepatic glucosensors are hepatocytes which are hyperpolarized by glucose or some metabolite of the glycolytic 
chain, related both to liver glycogen content and glucose uptake. In fact, glucose has a short-term hyperpolarizing effect on hepatocyte membranes (Meyer \& Scharrer, 1991), but this effect is independent of intracellular glucose utilization because the nonmetabolizable glucose antagonist 2-DG also hyperpolarized hepatocytes (Meyer \& Scharrer, 1991). In liver perfusion studies, Niijima (1969) showed that the discharge rate of hepatic vagal afferents decreased when D-glucose was added to the perfusion medium. In contrast, 2-DG increased the firing rate of hepatic vagal afferents (Niijima, 1983), and the effect of glucose on the spike frequency of hepatic vagal afferents was blocked by ouabain (Niijima, 1969, 1982, 1983). Taken together, these findings indicate that the effect of glucose on afferent nerve activity is related to glucose utilization and is mediated by the $\mathrm{Na}$ pump. Interestingly, experimental manipulation of $\mathrm{Na}$-pump activity also affects feeding. Several years ago we showed that intraperitoneal injection of ouabain stimulates feeding in rats (Langhans \& Scharrer, 1987a). The hyperphagic effect of ouabain was blocked by hepatic branch vagotomy, but not by peripheral anti-cholinergic blockade with atropine (Langhans \& Scharrer, 1987a), indicating that hepatic afferents are involved in the hyperphagic effect of ouabain. Further support for the assumption that the hyperphagic effect of ouabain originates in the liver is derived from recent studies, showing that remotely-controlled hepatic portal infusion of ouabain during the light phase increased spontaneous food intake in ad lib.-fed rats from $0.6(\mathrm{SE} 0.3) \mathrm{g}$ (control) to $1.9(\mathrm{SE} 0.4) \mathrm{g}(P<0.05)$, whereas equivalent infusions of ouabain into the inferior vena cava had no significant effect on feeding $(1 \cdot 1(\mathrm{SE} 0 \cdot 4) \mathrm{g}$ after ouabain $v .1 \cdot 0$ (SE 0.3) g after control infusion).

The opposite effects of glucose and 2-DG on feeding and afferent nerve activity together with the similar effects of both substances on hepatocyte membrane potential argue against a role of hepatocytes as glucosensors in the control of feeding. The results strongly indicate that vagal afferents respond directly to glucose and 2-DG and represent the hepatic glucosensors that affect feeding by monitoring their own rate of glucose utilization as originally proposed (Niijima, 1969). If there is a connection between hepatocytes and the glucose-sensitive neurons, the response of these glucosensors might be modulated by the hyperpolarization of hepatocytes induced by monosaccharides. Thus, direct response of the vagal glucosensors to glucose could be amplified by the hyperpolarization of hepatocyte membranes induced by glucose, whereas the direct effect of 2-DG on afferent nerve activity could be antagonized by the hyperpolarization of liver cell membranes (Meyer \& Scharrer, 1991). This antagonism may contribute to the absence of an hepatic component in the feeding response to 2-DG observed in several studies (for example Russel \& Mogenson, 1975). As many of the vagal afferents terminate in the wall of the hepatic portal vein (Berthoud et al. 1992), hepatic glucosensors seem to be well suited to monitor the incoming supply of glucose and to feed this information into the circuitry of the central nervous system that controls feeding.

Hepatic vagal afferents project to the nucleus of the solitari tract (NST; Hermann \& Rogers, 1985), which represents an important relay for visceral and gustatory afferents involved in the control of food intake (Powley \& Berthoud, 1986). From the NST the information can proceed rostrally to the hypothalamus directly or indirectly through the parabrachial nucleus. NST neurons and lateral-hypothalamic neurons respond to glucose in the same way as hepatic vagal afferents (Oomura \& Yoshimatsu, 1984). Furthermore, the lateral-hypothalamic glucose-sensitive neurons also respond to intraportal glucose 
application (Shimizu et al. 1983), suggesting that glucose-sensitive hepatic vagal afferents are linked to the lateral hypothalamus. In another study, however, the effect of intraportal glucose on the firing rate of lateral-hypothalamic neurons could be blocked by splanchnic nerve section (Schmitt, 1973). Therefore, the hepatic glucosensors might be linked also to the lateral hypothalamus via splanchnic afferents. Like vagal afferents, the majority of hepatic splanchnic afferents project to the NST (Rogers et al. 1984). Collectively, the neurophysiological data at hand indicate that the glucose-sensitive neurons in liver, NST and lateral hypothalamus are anatomically and functionally related and seem to represent a network that senses the availability of glucose and may be involved in glucose homeostasis as well as food intake regulation (Oomura \& Yoshimatsu, 1984; Fig. 1).

\section{Glucose metabolites and feeding}

First-pass fractional hepatic extraction of portal vein glucose by the liver is normally rather low (Radziuk et al. 1978; Ferranini et al. 1985), but the total amount of ingested glucose that ends up in the liver is considerable (Felig et al. 1975; Radziuk et al. 1978). These seemingly contradictory observations are explained by the fact that in vivo, because of the low phosphorylating capacity of hepatocytes for glucose (Foster, 1984), much glucose enters hepatic glycogen by an indirect route which requires transformation of ingested glucose into $C_{3}$ units by extrahepatic tissues (Newgard et al. 1983). As a result, plasma levels of lactate, which is quantitatively more important than pyruvate, increase during feeding. An increase in portal-vein-plasma lactate concentration in

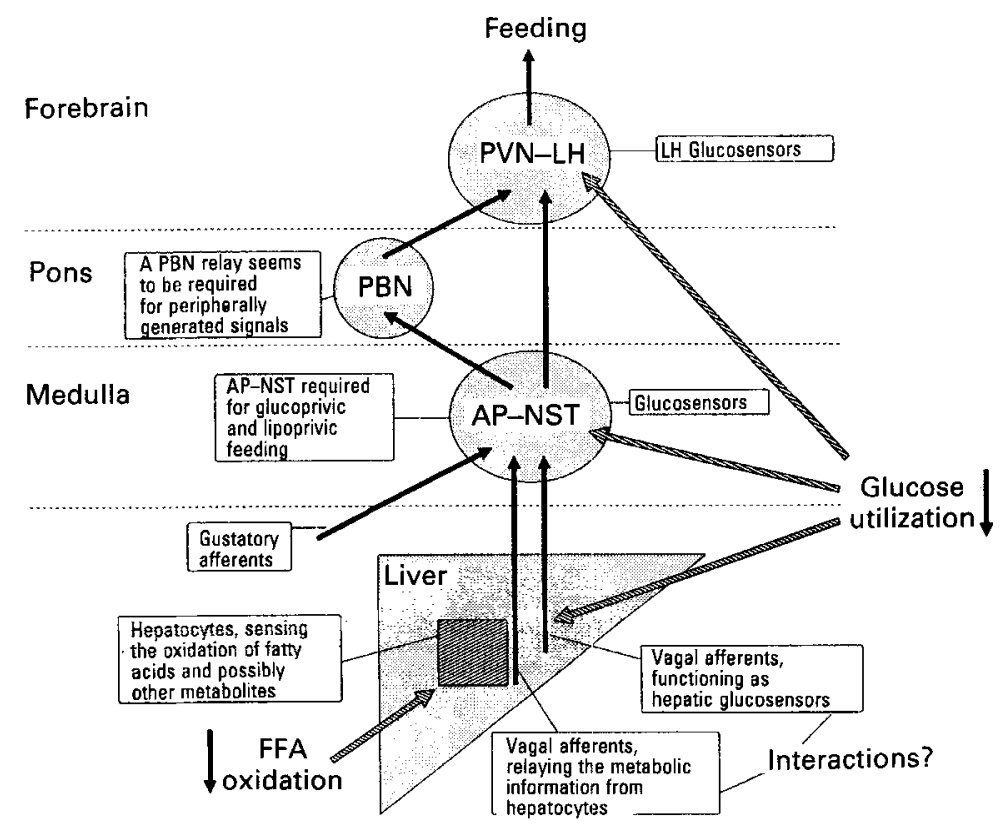

Fig. 1. Schematic view of the peripheral and central sites that are presumably involved in glucoprivic and lipoprivic feeding. FFA, free fatty acids; AP-NST, area postrema/nucleus of the solitari tract; PBN, parabrachial nucleus; PVN, paraventricular nucleus; $\mathrm{LH}$, lateral hypothalamus. For further details, see text. 
response to intragastric glucose loads has been observed in unrestrained chronicallycatheterized rats (Niewoehner et al. 1984; Kimura et al. 1988) and dogs (Shoemaker et al. 1963). Feeding after mild food deprivation in rats is also accompanied by an increase in portal vein and hepatic lactate concentration (Langhans, 1991) and in human subjects peripheral lactate concentration increases in response to carbohydrate meals (Felig et al. 1975; Surina et al. 1993). The meal-related and postprandial increase in plasma lactate may well contribute to satiation and/or satiety because lactate reduces food intake after parenteral administration in monkeys (Baile et al. 1970) and rats (Racotta \& Russek, 1977; Langhans et al. 1985a,b). Moreover, the hypophagic effect of lactate depends on hepatic vagal afferents (Langhans et al. 1985b) and seems to be related to hepatic oxidation of lactate beyond pyruvate (Langhans et al. 1985a). Taken together, these findings indicate that the hypophagic effect of lactate is mediated mainly by hepatic sensors which are linked to the brain through the vagus. Consistent with the assumption that the hypophagic effect of lactate originates in the liver, in recent experiments of ours (C. Silberbauer, D. Surina-Baumgartner and W. Langhans, unpublished results), remotely-controlled meal-related hepatic-portal infusions of lactate reduced the size of spontaneous meals in ad lib.-fed rats by $25 \%$ ( $1 \mathrm{mmol}$ lactate/rat $)$ and $68 \%(1.5 \mathrm{mmol}$ lactate/rat $)$. Meal duration was reduced by $31 \%(1 \mathrm{mmol})$ and $75 \%(1.5$ $\mathrm{mmol}$ ). Lactate did not affect the duration of the subsequent intermeal interval (IMI), but as a result of its effect on meal size, it increased the satiety ratio of the target meal (duration of subsequent IMI (min):meal size $(\mathrm{g})$ ) dramatically (81 and $156 \%$ for the 1 and $1.5 \mathrm{mmol}$ doses respectively). All in all, glucose metabolites, in particular lactate, may well be involved in the metabolic control of food intake, but further studies are necessary to test this idea.

\section{THE ROLE OF FATTY ACIDS IN THE METABOLIC CONTROL OF FEEDING}

\section{Fatty acid oxidation and feeding}

Consumption of diets high in fat has been associated with increased energy intake, body weight, and fat deposition in laboratory animals (see Kanarek \& Hirsch, 1977) as well as in humans (see Tremblay et al. 1989). The high-fat hyperphagia may be related to the high palatability of diets high in fat (see Pi-Sunyer, 1990). Furthermore, the energy density of most high-fat diets may play a role because often hyperphagia and increases in body weight do not occur when the energy density of the high-fat diet is reduced (for example Geary et al. 1979; Stubbs, 1996). Finally, the difference between postprandial metabolism of ingested carbohydrates and fats may also contribute to the high-fat hyperphagia. Less energy is required to store ingested fat as body fat than to store other nutrients in the adipose tissue, and the glycogen stores are much smaller than the fat depots. Thus, a major part of ingested carbohydrates is rapidly oxidized, whereas ingested fat seems to be predominantly stored (Flatt et al. 1985; Jéquier, 1994; Flatt, 1995). Accordingly, the RQ increases even in response to fat-rich meals (for example Surina et al. 1993).

In some experiments, unrestrained healthy males were able to compensate for covert manipulations of the energy content of a test meal regardless of its fat content (Foltin et al. 1990, 1992), suggesting that energy from ingested fat can affect feeding. However, most findings are consistent with the assumption that the short-term satiating effect of ingested fat, joule for joule, is lower than that of carbohydrates (Blundell et al. 1993: 
Rolls et al. 1994). This may be related to the incomplete oxidation of fatty acids from ingested fat as long as other fuels are available. Nevertheless, at least some ingested fat is oxidized postprandially. When healthy normal-weight men ate an isoenergetic highcarbohydrate or high-fat breakfast, the RQ initially increased under both conditions but was clearly lower after the high-fat breakfast (Surina et al. 1993). There are also individual differences in the ability to oxidize ingested fat, and a failure to increase lipid oxidation in response to increases in dietary fat content has been implicated in the development of obesity (for example Astrup et al. 1994). A larger part of ingested fat may be oxidized and fat may be more satiating in subjects adapted to high levels of dietary fat because chronic consumption of a high-fat diet enhances fatty acid oxidation. This is indicated by the increased rate of oxidation of acyl-CoA esters by isolated liver mitochondria (Bremer \& Osmundsen, 1984), and by decreases in glucose oxidation observed in rats adapted to a high-fat diet (Geary et al. 1979). Accordingly, in human subjects adapted to various levels of dietary fat overall substrate utilization, as indicated by RQ, parallels diet composition (Rumpler et al. 1991; Verboeket-van de Venne et al. 1994). Finally, the failure of a single high-fat meal to decrease the $R Q$ acutely does not exclude the possibility that fatty acid oxidation in a particular organ like the liver increases in response to a fat-containing meal (see p. 506). All in all, fatty acids are major fuels, and it is reasonable to assume that fatty acid oxidation somehow contributes to the metabolic control of eating.

Several lines of evidence indicate that fatty acids suppress hunger: (1) hunger decreases as soon as mobilization of depot fat is fully activated during fasting (Hamilton, 1969), (2) infusion of lipids reduced food intake in various species (Woods et al. 1984; Walls \& Koopmans, 1989), and (3) inhibition of fatty acid oxidation in rats is associated with enhanced feeding (lipoprivic feeding), especially when a fat-rich diet is consumed. We found that inhibiting $\beta$-oxidation of fatty acids with mercaptoacetate was associated with increased food intake in rats fed on a fat-rich diet ( $\mathrm{g} / \mathrm{kg} ; 180 \mathrm{fat}, 460 \mathrm{starch})$, but not in rats fed on a low-fat diet (g/kg; 33 fat, 770 starch; Scharrer \& Langhans, 1986). The hyperphagic effect of mercaptoacetate was more pronounced during the day than during the night, probably because lipolysis and fatty acid oxidation in the rat is accelerated during the day (LeMagnen, 1983). Mercaptoacetate blocks fatty acid oxidation by inhibiting the acyl-CoA-dehydrogenases located in the mitochondrial matrix and, therefore, impairs mitochondrial $\beta$-oxidation of fatty acids (Bauché et al. 1981). Further evidence for the importance of mitochondrial oxidation in the satiety effect of fatty acids is derived from findings showing that methyl palmoxirate, an inhibitor of carnitine palmitoyltransferase, increased food intake in rats fed on a diet high in long-chain fatty acids, but did not affect food intake in rats fed on a diet high in medium-chain fatty acids, which do not require the enzyme carnitine palmitoyltransferase (EC 2.3.1.21) for mitochondrial uptake and oxidation (Friedman et al. 1990). Mercaptoacetate increased food intake by primarily reducing the latency to eat after injection and the duration of the subsequent IMI without significantly affecting the size of the first meal (Langhans \& Scharrer, 1987b). This indicates that fatty acid oxidation contributes to the maintenance of postprandial satiety.

\section{Hepatic sensors for fatty acids}

There is ample evidence that hepatic sensors can monitor the utilization of other metabolites as well as glucose and that information derived from these metabolic sensors 
also affects feeding. For instance, the reduction of spontaneous food intake brought about by continuous total parenteral nutrition was markedly attenuated by dissection of the hepatic branch of the vagus (Yang et al. 1992). This effect was due to an increase in meal size and meal frequency compared with sham-operated rats receiving total parenteral nutrition (Yang et al. 1992), indicating that hepatic signals triggered by a mixture of nutrients play a role in satiation as well as in satiety. Fatty acid oxidation presumably also affects feeding in part through hepatic sensors. We found that the hyperphagia of rats fed on a $180 \mathrm{~g}$ fat $/ \mathrm{kg}$ diet in response to mercaptoacetate was antagonized by hepatic branch vagotomy (Langhans \& Scharrer, 1987a). More recently, Beverly et al. (1994b) confirmed these findings; in addition they showed that hepatic branch vagotomy eliminated the stimulating effect of mercaptoacetate on feeding in rats receiving total parenteral nutrition (Beverly et al. 1994b). There is one report in which hepatic branch vagotomy failed to attenuate the hyperphagic effect of mercaptoacetate significantly (Ritter et al. 1988). This discrepancy cannot readily be explained, but the residual feeding response to mercaptoacetate in rats with hepatic branch vagotomy suggests that extrahepatic sensors may in part be involved in the effect of mercaptoacetate on food intake, or that hepatic afferents that are spared in hepatic branch vagotomy contribute. It should be noted in this context that hepatic metabolic sensors may be linked also to the brain through splanchnic afferents (Schmitt, 1973). Since mercaptoacetate retained its potency to stimulate feeding after peripheral blockade of cholinergic transmission by atropine methyl nitrate (Langhans \& Scharrer, 1987c), fatty acid oxidation seems to affect feeding at least in part through vagal afferents and not efferents. Moreover, capsaicin pretreatment, subdiaphragmatic vagotomy, and lesions of the vagal sensory terminal fields in the AP-NST abolished lipoprivic feeding (Ritter \& Taylor, 1989, 1990), and feeding could not be elicited by injection of mercaptoacetate into the lateral or fourth ventricle of rats (Ritter \& Taylor, 1989). All these findings are consistent with the assumption that the metabolic sensors involved in lipoprivic feeding reside primarily in the liver, and possibly other viscera. Fig. 1 schematically outlines the peripheral and central sites that are presumably involved in lipoprivic feeding.

A rapid increase in blood ketone body levels, reflecting an increase in hepatic fatty acid oxidation, has been observed after ingestion of pure medium-chain triacylglycerols in man (Pi-Sunyer et al. 1969) and after milk ingestion in calves (Senn et al. 1995). A transient meal-related increase in the peripheral blood $\beta$-hydroxybutyrate (BHB) level can be observed also after ingestion of a fat-rich meal in human subjects. In forty-three healthy male volunteers, mean plasma BHB transiently rose in response to consumption of an American-style high-fat breakfast (g/kg; 330 carbohydrate, 520 fat, 150 protein) from 37 (SE 2) to 47 (SE 3) and 45 (SE 2) $\mu \mathrm{mol} / 1$ at 30 and $50 \mathrm{~min}$ after meal onset $(P<0 \cdot 05)$. Thereafter, plasma BHB continuously decreased and levelled off at about 10 $\mu \mathrm{mol} / \mathrm{l}$ at $150 \mathrm{~min}$. In rats adapted to a $180 \mathrm{~g}$ fat, $460 \mathrm{~g}$ starch diet, the liver continued to release $\mathrm{BHB}$ after a meal, and at $30 \mathrm{~min}$ after the meal the hepatic release of BHB was higher compared with meal onset (Surina-Baumgartner et al. 1996), showing that rat liver oxidizes considerable amounts of fatty acids in response to a fat- and carbohydraterich meal. Interestingly, the hepatic BHB release in rats was observed despite a decrease in aortal plasma BHB. If this holds for human subjects, hepatic fatty acid oxidation and $\mathrm{BHB}$ release in response to a fat-rich meal might continue after peripheral plasma $\mathrm{BHB}$ starts to decline. Given the fact that mercaptoacetate-induced feeding depends on sensory, presumably hepatic, afferents (Langhans \& Scharrer, 1987c; Ritter \& Taylor, 


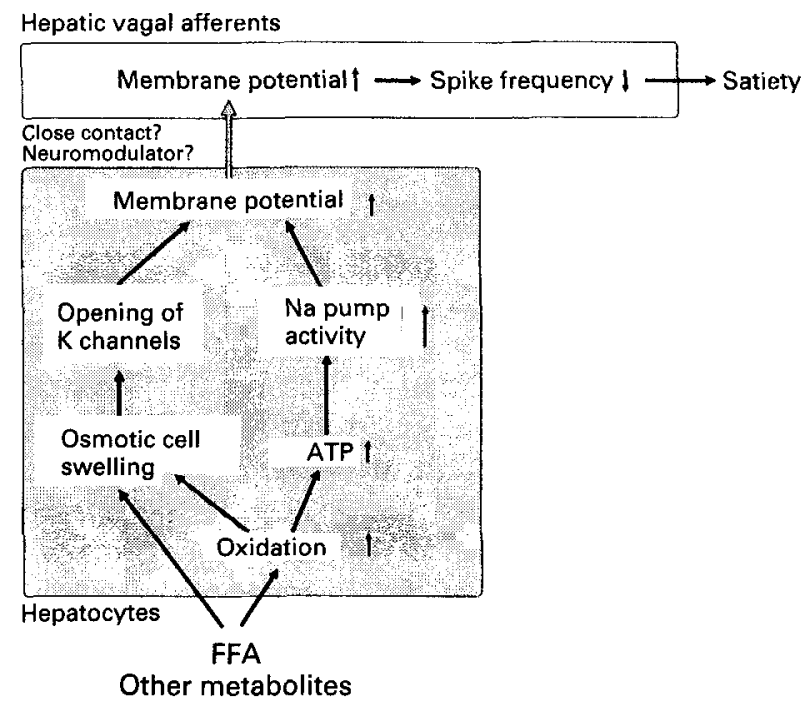

Fig. 2. Hypothetical coding mechanism for hepatocytes functioning as sensors for the oxidation of fatty acids and perhaps other metabolites in the control of feeding. FFA, free fatty acids. For further details, see p. 507.

1989, 1990; Beverly et al. 1994b), these findings are consistent with a role of hepatic fatty acid oxidation in feeding control, at least when it is enhanced, as during continuous fat-rich feeding or at times of fat mobilization. More specifically, the data fit the hypothesis that fatty acid oxidation contributes to the maintenance of satiety (Langhans \& Scharrer, 1987b). Nevertheless, it should be noted that a role of short-term fluctuations in fatty acid oxidation in the meal-to-meal control of feeding is still unproven.

What is the nature of the putative hepatic sensors for fatty acid oxidation? It is unlikely that fatty acids are utilized and sensed directly by vagal afferents. As hepatocytes are able to oxidize almost all fuels and rely in particular on fatty acid oxidation (Seifter \& Englard, 1988) for ATP generation, hepatocytes may contribute to the metabolic control of feeding by sensing the oxidation of fatty acids. Fatty acids stimulate respiration and ATP synthesis in isolated hepatocytes, and a large part of this ATP is utilized by the Na pump, as seen by the fact that ouabain partially (50-60\%) inhibited the stimulatory effect of fatty acids on respiration (Plomp et al. 1985). In liver perfusion studies hepatocyte membranes were hyperpolarized by palmitate (Dambach \& Friedmann, 1974; Rossi et al. 1995). This effect was more pronounced when the livers were obtained from animals fed on a fat-rich diet, and it was reversed by inhibitors of fatty acid oxidation (Rossi et al. 1995), indicating that oxidation of palmitate leads to hepatocyte hyperpolarization. The hyperpolarizing effect of palmitate on hepatocyte membranes was antagonized also by ouabain and by K-channel blockers, suggesting that Na-pump activation and an opening of $K$ channels is involved (Rossi et al. 1995). All in all, mitochrondrial oxidation of fatty acids may affect hepatocyte membrane potential through cytosolic ATP and Na-pump activity or through $\mathrm{K}$ efflux due to cell swelling and the ensuing opening of K channels (Fitz \& Scharschmidt, 1987; Meyer \& Scharrer, 1991; Rossi et al. 1995). The latter possibility may apply also to ketone bodies resulting from 
enhanced fatty acid oxidation (Rossi et al. 1995). Fig. 2 depicts how fatty acid oxidation might lead to hepatocyte hyperpolarization.

The assumption that hepatocytes function as metabolic sensors for the oxidation of fatty acids, and perhaps other substrates, requires that the metabolic information is somehow transferred to hepatic afferent nerves. Using anterograde tracing of the hepatic vagal innervation, Berthoud et al. (1992) failed to detect afferent nerve endings in rat liver parenchyma. Recently, the neurofilament protein 200 was detected immunohistochemically in close association with hepatocytes in certain areas of rat liver (Friedman et al. 1994), suggesting that rat liver parenchyma is innervated. Yet, this technique cannot differentiate between efferent and afferent nerve fibres. If there is no connection between hepatocytes and afferent nerves, hepatocytes might perhaps release some as yet unidentified modulator of nerve activity (Fig. 2). For fatty acid oxidation, even BHB, which is readily taken up and oxidized by peripheral nerves (Greene \& Winegrad, 1979), might serve such a function. These possibilities have not yet been thoroughly investigated. All in all, a sensory function of hepatocytes in the metabolic control of feeding appears possible, but has still not been proved.

Reports of an increase in food intake after administration of ouabain (see p. 502) or of the fructose analogue 2,5-anhydro-mannitol (2,5-AM; Tordoff et al. 1988) are consistent with the hypothesis that Na-pump activity and ATP availability play a role in the sensory process of the hepatic sensors for the oxidation of fatty acids and perhaps other substrates that are being implicated in feeding control. In addition to inhibiting gluconeogenesis and glycogenolysis (Hanson et al. 1984), 2,5-AM has been shown to decrease the cytosolic ATP:ADP in isolated hepatocytes (Stevens et al. 1985). The hyperphagic effect of 2,5-AM originates in the liver because (1) rats began feeding sooner and ate more food during hepatic portal than during intrajugular infusion of 2,5-AM, (2) hepatic branch vagotomy blocked the feeding response to 2,5-AM, and (3) after administration of radioactive 2,5-AM, significant quantities of radioactivity were found in the liver but not in the brain (Tordoff et al. 1991). An in vivo study using ${ }^{31} \mathrm{P}$ NMR technique also showed that 2,5-AM is rapidly phosphorylated in the liver, trapping hepatic phosphate and decreasing ATP (Rawson et al. 1994a); these changes occur in a time-frame that parallels the feeding response. In addition, the feeding response to 2,5-AM was attenuated by pretreatment with exogenous phosphate (Rawson \& Friedman, 1994) and administration of L-ethionine, which decreases ATP by a different mechanism, also stimulates feeding (Rawson et al. 1994b).

\section{INTERACTIONS BETWEEN FATTY ACID OXIDATION AND UTILIZATION OF OTHER FUELS}

Several findings indicate that the utilization of glucose and other metabolites, in particular fatty acids, exerts a coordinated control over feeding behaviour. Combined treatment of rats with 2-DG, which inhibits glucose utilization, and methyl palmoxyrate, which inhibits fatty acid oxidation, increased food intake of rats synergistically (Friedman \& Tordoff, 1986). This synergism was observed at doses of the two agents that alone did not increase food intake (Friedman \& Tordoff, 1986), indicating that sub-threshold changes in glucose and fatty acid oxidation combine to stimulate feeding. Similar results were obtained with combined administration of 2-DG and nicotinic acid, which blocks fat mobilization (Even et al. 1988). In addition, parenterally- and 
intragastrically-administered glucose proved to be more satiating when the rate of fatty acid oxidation was high (Geary et al. 1979). Moreover, during total parenteral nutrition in rats, glucoprivic feeding seemed to be neutralized by the oxidation of the infused fatty acids because $2-D G$ stimulated feeding only after hepatic branch vagotomy or when fatty acid oxidation was simultaneously inhibited by mercaptoacetate (Beverly et al. 1994b). Further indirect evidence for a substitution of glucose by free fatty acids as fuels in the metabolic control of feeding is derived from studies of Scharrer's group (Scharrer et al. 1993; Delprete \& Scharrer, 1994), who found that hepatic branch vagotomy either attenuated or enhanced glucoprivic feeding depending on the test conditions. This indicates that systemic administration of $2-\mathrm{DG}$ produces an hyperphagic and an hypophagic stimulus which are both mediated by the hepatic branch of the vagus, and the experimental conditions seem to determine which one is dominant (Scharrer et al. 1993). One possible explanation for the hypophagic stimulus is enhanced hepatic fatty acid oxidation resulting from $2-D G$-mediated sympathetic nervous system activation and the ensuing lipolysis (Scharrer et al. 1993). Hence, the findings are consistent with the hypothesis that glucoprivic feeding is influenced by the availability of alternative fuels, in particular free fatty acids.

It should also be noted in this context that the stimulation of feeding by 2-DG is not exclusively and directly coupled to acute glucoprivation, and can be blocked by other fuels than glucose. Ritter et al. (1978) found that 2-DG-induced feeding still occurs when food is withheld for 6 or $8 \mathrm{~h}$ after 2-DG administration, until the glucoprivic stimulus has presumably dissipated. The delayed feeding response to 2-DG was diminished or prevented by various metabolic fuels that were infused or ingested before the presentation of food (Bellin \& Ritter, 1981; Ritter et al. 1981). Similarly, systemic glucoprivation produces hunger for energy rather than specific carbohydrate hunger as previously thought (Kanarek et al. 1983), because in one study (Delprete \& Scharrer, 1992), 2-DG injected intraperitoneally during the light phase stimulated feeding also in rats fed on a high-fat diet. Similarly, mercaptoacetate stimulated carbohydrate as well as fat intake in rats selecting from isoenergetic high-fat $(400 \mathrm{~g} \mathrm{fat} / \mathrm{kg})$ and low-fat $(\mathrm{g} / \mathrm{kg} ; 33 \mathrm{fat}, 770$ starch) diets (see Langhans \& Scharrer, 1992), indicating that inhibition of fatty acid oxidation also generates an unspecific hunger signal.

As already mentioned, peripherally generated metabolic signals in the control of feeding are transmitted to the forebrain through vagal and perhaps splanchnic afferents, the NST and the PVN (Powley \& Berthoud, 1986; Ritter \& Taylor, 1989, 1990; Grill et al. 1995; Fig. 1). The final integration occurs in the hypothalamus and involves various neurochemicals (see Leibowitz, 1988, 1992). Yet some integration may also occur in the liver, for instance if the afferent nerves functioning as peripheral glucosensors are influenced by metabolic signals from hepatocytes (Fig. 1). Moreover, in addition to sensing the oxidation of free fatty acids, hepatocytes may also monitor the oxidation of other metabolites, in particular lactate and pyruvate, which both hyperpolarize hepatocyte membranes (Dambach \& Friedmann, 1974) and reduce food intake, presumably through an hepatic mechanism (Langhans et al. 1985a,b).

The utilization of several metabolites could also combine to produce a signal in the control of feeding by body fat (Kennedy, 1953). The original version of this lipostatic hypothesis proposed that circulating fuels, the plasma concentrations of which reflect the level of adiposity, are instrumental in the compensatory adjustments of voluntary food intake that can be seen in response to experimental modifications of body weight. This 
concept is attractive because the body's energy stores are in dynamic equilibrium with the circulating energy pool (Van Itallie \& Kissileff, 1983). For instance, an increase in adiposity results in an increased release of fatty acids and glycerol in the circulation (MacDonald et al. 1976). It is interesting in this context that adipose tissue is also an important source of lactate (Lovejoy et al. 1990), and that adipocyte lactate production is directly related to the level of adiposity (DiGirolamo et al. 1992). Therefore, lactate also may contribute to the lipostatic control of food intake. Although direct evidence for a role of a particular metabolite in the control of food intake by body fat is not yet available (see Scharrer \& Langhans, 1990), an integrated signal from the enhanced utilization of free fatty acids and other metabolites including lactate is conceivable.

In summary, it is generally accepted that the utilization of glucose and other metabolites (in particular fatty acids) plays an important role in the control of feeding. However, despite more than 40 years of intensive research, several questions concerning the exact nature and mechanisms of the glucostatic and metabolic control of feeding remain to be answered.

\section{REFERENCES}

Adair, E. R., Miller, N. E. \& Booth, D. A. (1968). Effects of continuous intravenous infusion of nutritive substances on consummatory behavior in the rat. Communications in Behavioral Biology A2, 25-37.

Astrup, A., Buemann, B., Christensen, N. J. \& Toubro, S. (1994). Failure to increase lipid oxidation in response to increasing dietary fat content in formerly obese women. American Journal of Physiology 266, E592-E599.

Bach, A. C. \& Babayan, V. K. (1982). Medium-chain triglycerides: an update. American Journal of Clinical Nutrition 36, 950-962.

Baile, C. A., Zinn, W. M. \& Mayer, J. (1970). Effects of lactate and other metabolites on food intake of monkeys. American Journal of Physiology 219, 1606-1613.

Bauché, F., Sabourault, D., Giudicelli, Y., Nordmann, J. \& Nordmann, R. (1981). 2-Mercaptoacetate administration depresses the $\beta$-oxidation pathway through an inhibition of long-chain acyl-CoA dehydrogenase activity. Biochemical Journal 196, 803-809.

Bellin, S. I. \& Ritter, S. (1981). Disparate effects of infused nutrients on delayed glucoprivic feeding and hypothalamic norepinephrine turnover. Journal of Neuroscience 1, 1347-1353.

Bellinger, L. L., Trietley, G. J. \& Bernardis, L. L. (1976). Failure of portal glucose and adrenaline infusions or liver denervation to affect food intake in dogs. Physiology and Behavior 16, 299-304.

Berthoud, H.-R., Kressel, M. \& Neuhuber, W. L. (1992). An anterograde tracing study of the vagal innervation of rat liver, portal vein and biliary system. Anatomy and Embryology 186, 431-442.

Berthoud, H.-R. \& Mogenson, G. J. (1977). Ingestive behavior after intracerebral and intracerebroventricular infusions of glucose and 2-deoxy-D-glucose. American Journal of Physiology 233, R127-R133.

Beverly, J. L., Yang, Z.-J. \& Meguid, M. M. (1994a). Factors influencing compensatory feeding during parenteral nutrition in rats. American Journal of Physiology 266, R1928-R1932.

Beverly, J. L., Yang, Z.-J. \& Meguid, M. M. (1994b). Hepatic vagotomy effects on metabolic challenges during parenteral nutrition in rats. American Journal of Physiology 266, R646-R649.

Blundell, J. E., Burley, V. J., Cotton, J. R. \& Lawton, C. L. (1993). Dietary fat and the control of energy intake: evaluating the effects of fat on meal size and postmeal satiety. American Journal of Clinical Nutrition 57, Suppl., S772-S778.

Booth, D. A. (1972). Postabsorptively induced suppression of appetite and the energostatic control of feeding. Physiology and Behavior 9, 199-202.

Bremer, J. \& Osmundsen, H. (1984). Fatty acid oxidation and its regulation. In Fatty Acid Oxidation and its Regulation, pp. 113-154 [S. Numa, editor]. Amsterdam: Elsevier.

Campfield, L. A. \& Smith, F. J. (1990). Systemic factors in the control of food intake - Evidence for patterns as signals. In Handbook of Behavioral Neurobiology. Neurobiology of Food and Fluid Intake, vol. 10, pp. 183-206 [E. M. Stricker, editor]. New York: Plenum Press.

Campfield, L. A., Smith, F. J. \& Brandon, P. (1985). On-line continuous measurement of blood glucose and meal pattern in free-feeding rats: the role of glucose in meal initiation. Brain Research Bulletin 14, 606-616. 
Campfield, L. A., Smith, F. J., Rosenbaum, M. \& Hirsch, J. (1995). Transient declines in blood glucose precede increased hunger ratings in humans. Appetite 24, 78.

Dambach, G. \& Friedmann, N. (1974). Substrate-induced membrane potential changes in the perfused rat liver. Biochimica et Biophysica Acta 367, 366-370.

Davis, J. D., Wirtshafter, D., Asin, K. E. \& Brief, D. (1981). Sustained intracerebroventricular infusion of brain fuels reduces body weight and food intake in rats. Science 212, 81-82.

Davis, M. A., Williams, P. E. \& Cherrington, A. D. (1984). Effect of a mixed meal on hepatic lactate and gluconeogenetic precursor metabolism in dogs. American Journal of Physiology 247, E362-E369.

Delprete, E. \& Scharrer, E. (1990). Hepatic branch vagotomy attenuates the feeding response to 2-deoxy-Dglucose in rats. Experimental Physiology 75, 259-261.

Delprete, E. \& Scharrer, E. (1992). Effects of 2-deoxy-D-glucose on food intake of rats are affected by diet composition. Physiology and Behavior 51, 951-956.

Delprete, E. \& Scharrer, E. (1994). Circadian effects of hepatic branch vagotomy on the feeding response to 2-deoxy-D-glucose in rats. Journal of the Autonomic Nervous System 46, 27-36.

DiGirolamo, M., Newby, D. F. \& Lovejoy, J. (1992). Lactate production in adipose tissue: a regulated function with extra-adipose implications. FASEB Journal 6, 2405-2412.

Even, P., Coulaud, H. \& Nicolaidis, S. (1988). Integrated metabolic control of food intake after 2-deoxy-Dglucose and nicotinic acid injection. American Journal of Physiology 255, R82-R89.

Even, P. \& Nicolaidis, S. (1985). Spontaneous and 2DG induced metabolic changes and feeding: The ischymetric hypothesis. Brain Research Bulletin 15, 429-435.

Even, P. \& Nicolaidis, S. (1986). Short-term control of feeding, limitation of the glucostatic theory. Brain Research Bulletin 17, 621-626.

Felig, P., Wahren, J. \& Hendler, R. (1975). Influence of oral glucose ingestion on splanchnic glucose and gluconeogenetic substrate metabolism in man. Diabetes 24, 468-475.

Ferranini, E., Bjorkman, O., Reichard, G. A. Jr, Pilo, A., Olsson, M., Wahren, J. \& DeFronzo, R. A. (1985). The disposal of an oral glucose load in healthy subjects. Diabetes 34, 580-588.

Fitz, J. G. \& Scharschmidt, B. F. (1987). Regulation of transmembrane electrical potential gradient in rat hepatocytes in situ. American Journal of Physiology 252, G56-G64.

Flatt, J. P. (1995). Use and storage of carbohydrate and fat. American Journal of Clinical Nutrition 61, Suppl., S952-S959.

Flatt, J. P., Ravussin, E., Acheson, K. J. \& Jéquier, E. (1985). Effects of dietary fat on postprandial substrate oxidation and on carbohydrate and fat balances. Journal of Clinical Investigation 76, 1019-1024.

Foltin, R. W., Fischman, M. W., Moran, T. H., Rolls, B. \& Kelly, T. H. (1990). Caloric compensation for lunches varying in fat and carbohydrate content by humans in a residential laboratory. American Journal of Clinical Nutrition 52, 969-980.

Foltin, R. W, Rolls, B. J., Moran, T. H., Kelly, T. H., McNelis, A. L. \& Fischman, M. W. (1992). Caloric, but not macronutrient, compensation by humans for required-eating occasions with meals and snack varying in fat and carbohydrate. American Journal of Clinical Nutrition 55, 331-342.

Foster, D. W. (1984). From glycogen to ketones - and back. Diabetes 33, 1188-1199.

Friedman, M. I., Ketchum, M., Ulrich, P., Broslin, P. A. S. \& DellaCorte, C. (1994). Evidence for innervation of the hepatic parenchyma in the rat. Society for Neuroscience Abstracts $\mathbf{2 0}, 1226$.

Friedman, M. I., Ramirez, I., Bowden, C. R. \& Tordoff, M. G. (1990). Fuel partitioning and food intake: Role for mitochondrial fatty acid transport. American Journal of Physiology 258, R216-R221.

Friedman, M. I. \& Stricker, M. E. (1976). The physiological psychology of hunger, a physiological perspective. Psychological Reviews 83, 409-431.

Friedman, M. I. \& Tordoff, M. G. (1986). Fatty acid oxidation and glucose utilization interact to control food intake in rats. American Journal of Physiology 251, R840-R845.

Geary, N., Scharrer, E., Freudlsperger, R. \& Raab, W. (1979). Adaptation to high fat diet and carbohydrateinduced satiety in the rat. American Journal of Physiology 237, R139-R146.

Geiselman, P. J. (1984). Food intake following intraduodenal and hepatic-portal infusion of hexoses in the rabbit: evidence that hexose administration can increase subsequent chow intake. Nutrition and Behavior 2 , 77-87.

Greene, D. A. \& Winegrad, A. I. (1979). In vitro studies of the substrates for energy production and the effects of insulin on glucose utilization in the neural components of peripheral nerve. Diabetes 28, 878-887.

Grill, H. J., Friedman, M. I., Norgren, R., Scalera, G. \& Seeley, R. (1995). Parabrachial nucleus lesions impair feeding response elicited by 2,5-anhydro-D-mannitol. American Journal of Physiology 268, R676-R682. 
Hamilton, C. L. (1969). Problems of refeeding after starvation in the rat. Annals of the New York Academy of Sciences 157, 1004-1017.

Hanson, R. L., Ho, R. S., Wisenberg, J. J., Simpson, R., Younathan, E. S. \& Blair, J. B. (1984). Inhibition of gluconeogenesis and glycogenolysis by 2,5-anhydro-D-mannitol. Journal of Biological Chemistry 259, 218-223.

Hermann, G. E. \& Rogers, R. C. (1985). Convergence of vagal and gustatory afferent input within the parabrachial nucleus of the rat. Journal of the Autonomic Nervous System 13, 1-17.

Himmi, T., Boyer, A. \& Orsini, J. C. (1988). Changes in lateral hypothalamic neuronal activity accompanying hyper- and hypoglycemias. Physiology and Behavior 44, 347-354.

Jéquier, E. (1994). Carbohydrates as a source of energy. American Journal of Nutrition 59, Suppl., S682-S685.

Kanarek, R. B. \& Hirsch, J. B. (1977). Dietary-induced overeating in experimental animals. Federation Proceedings 36, 154-158.

Kanarek, R. B., Marks-Kaufman, R., Ruthazer, R. \& Gualtieri, L. (1983). Increased carbohydrate consumption by rats as a function of 2-deoxy-D-glucose administration. Pharmacology Biochemistry and Behavior 18, 47-50.

Katzeff, H. L. \& Danforth, E. Jr (1989). Decreased thermic effect of a mixed meal during overnutrition in human obesity. American Journal of Clinical Nutrition 50, 915-921.

Kennedy, G. C. (1953). Role of depot fat in the hypothalamic control of food intake in the rat. Proceedings of the Royal Society (London) 140B, 578-592.

Kimura, R. E., LaPine, T. R. \& Manford Gooch, W. III (1988). Portal venous and aortic glucose and lactate changes in a chronically catheterized rat. Pediatric Research 23, 235-240.

Langhans, W. (1991). Hepatic and intestinal handling of metabolites during feeding in rats. Physiology and Behavior 49, 1203-1209.

Langhans, W., Damaske, U. \& Scharrer, E. (1985a). Different metabolites might reduce food intake by the mitrochondrial generation of reducing equivalents. Appetite 6, 143-152.

Langhans, W., Egli, G. \& Scharrer, E. (1985b). Selective hepatic vagotomy eliminates the hypophagic effect of different metabolites. Journal of the Autonomic Nervous System 13, 255-262.

Langhans, W., Geary, N. \& Scharrer, E. (1982). Liver glycogen content decreases during meals in rats. American Journal of Physiology 243, R450-R453.

Langhans, W., Pantel, K., Müller-Schell, W., Eggenberger, E. \& Scharrer, E. (1984). Hepatic handling of pancreatic glucagon and glucose during meals in rats. American Joumal of Physiology 247, R827-R832.

Langhans, W. \& Scharrer, E. (1987a). Evidence for a role of the sodium pump of hepatocytes in the control of food intake. Journal of the Autonomic Nervous System 20, 199-205.

Langhans, W. \& Scharrer, E. (1987b). Role of fatty acid oxidation in control of meal pattern. Behavioral and Neural Biology 47, 7-16.

Langhans, W. \& Scharrer, E. (1987c). Evidence for a vagally-mediated satiety signal derived from hepatic fatty acid oxidation. Journal of the Autonomic Nervous System 18, 13-18.

Langhans, W. \& Scharrer, E. (1992). Metabolic control of eating. In Metabolic Control of Eating, Energy Expenditure and the Bioenergetics of Obesity. World Review of Nutrition and Dietetics, vol. 70, pp. 1-67 [A. P. Simopoulos, editor]. Basel: Karger.

Larue-Achagiotis, C. \& LeMagnen, J. (1981). Metabolic correlates of the effects of 2-deoxy-glucose on meal size and post-meal satiety in rats. Physiology and Behavior 26, 193-196.

Leathwood, P. \& Pollet, P. (1988). Effects of slow release carbohydrates in the form of bean flakes on the evolution of hunger and satiety in man. Appetite 10, 1-11.

Leibowitz, S. F. (1988). Hypothalamic paraventricular nucleus: interaction between $\alpha_{2}$-noradrenergic system and circulating hormones and nutrients in relation to energy balance. Neuroscience and Biobehavioral Reviews 12, 101-104.

Leibowitz, S. F. (1992). Neurochemical-neuroendocrine systems in the brain controlling macronutrient intake and metabolism. Trends in Neurosciences 15, 491-497.

LeMagnen, J. (1983). Body energy balance and food intake: A neuroendocrine regulatory mechanism. Physiological Reviews 63, 314-386.

Louis-Sylvestre, J. \& LeMagnen, J. (1980). A fall in blood glucose level precedes meal onset in free-feeding rats. Neuroscience and Biobehavioral Reviews 4, 13-15.

Lovejoy, J., Mellen, B. \& DiGirolamo, M. (1990). Lactate generation following glucose ingestion: Relation to obesity, carbohydrate tolerance and insulin sensitivity. International Journal of Obesity 14, 843-855.

MacDonald, I. A., Rothwell, N. J. \& Stock, M. J. (1976). Lipolytic and lipogenic activities of adipose tissue during spontaneous fat depletion and repletion. Proceedings of the Nutrition Society 35, 129A-130A. 
MacLagan, N. F. (1937). The role of appetite in the control of body weight. Journal of Physiology $\mathbf{9 0 , 3 8 5 - 3 9 4 . ~}$ Mayer, J. (1953). Glucostatic mechanism of regulation of food intake. New England Journal of Medicine 249, 13-16.

Meyer, A. H. \& Scharrer, E. (1991). Hyperpolarization of the cell membrane of mouse hepatocytes by metabolizable and non-metabolizable monosaccharides. Physiology and Behavior 50, 351-355.

Miselis, R. R. \& Epstein, A. N. (1975). Feeding induced by intracerebroventricular 2-deoxy-D-glucose in the rat. American Journal of Physiology 229, 1438-1447.

Müller, K., Scharrer, E. \& Zucker, H. (1967). Aufhebung eines durch die Mahlzeitenfolge gesetzten 12-Std-Rhythmus der Blugucosekonzentration durch Änderung der Nahrungszusammensetzung. Naturwissenschaften 54, 201-202.

Murname, J. M. \& Ritter, S. (1985). Intraventricular alloxan impairs feeding to both central and systemic glucoprivation. Physiology and Behavior 34, 609-613.

Newgard, C. B., Moore, S. V., Foster, D. W. \& McGarry, J. D. (1983). Efficient hepatic glycogen synthesis in refeeding rats requires continued carbon flow through the gluconeogenetic pathway. Journal of Biological Chemistry 259, 6948-6963.

Nicolaidis, S. (1981). Lateral hypothalamic control of metabolic factors related to feeding. Diabetologia 20 , $426-441$.

Nicolaidis, S. \& Rowland, N. (1976). Metering of intravenous versus oral nutrients and regulation of energy balance. American Journal of Physiology 231, 661-668.

Niewoehner, C. B., Gilboe, D. P. \& Nuttal, F. Q. (1984). Metabolic effects of oral glucose in the liver of fasted rats. American Journal of Physiology 246, E89-E94.

Niijima, A. (1969). Afferent impulse discharges from glucoreceptors in the liver of the guinea pig. Annals of the New York Academy of Sciences 157, 690-700.

Niijima, A. (1982). Glucose-sensitive afferent nerve fibres in the hepatic branch of the vagus nerve in the guinea-pig. Journal of Physiology 332, 315-323.

Niijima, A. (1983). Glucose-sensitive afferent nerve fibers in the liver and their role in food intake and blood glucose regulation. Journal of the Autonomic Nervous System 9, 207-220.

Novin, D., O'Farrel, L., Acevedo-Cruz, A. \& Geiselman, P. J. (1991). The metabolic bases for 'paradoxical' and normal feeding. Brain Research Bulletin 27, 435-438.

Novin, D., Robinson, K., Culbreth, L. A. \& Tordoff, M. G. (1985). Is there a role for the liver in control of food intake. American Journal of Clinical Nutrition 42, 1050-1062.

Novin, D., Sanderson, J. O. \& VanderWeele, D. A. (1974). The effect of isotonic glucose on eating as a function of feeding condition and infusion site. Physiology and Behavior 13, 3-7.

Novin, D., VanderWeele, D. A. \& Rezek, M. (1973). Infusion of 2-deoxy-D-glucose into the hepatic portal system causes eating: Evidence for peripheral glucoreceptors. Science 181, 858-860.

Oomura, Y. (1976). Significance of glucose, insulin, and free fatty acid on the hypothalamic feeding and satiety neurons. In Hunger: Basic Mechanisms and Clinical Implications, pp. 145-157 [D. Novin, W. Wyrwicka and G. Bray, editors]. New York: Raven Press.

Oomura, Y. \& Yoshimatsu, H. (1984). Neural network of glucose monitoring system. Journal of the Autonomic Nervous System 10, 359-372.

Pi-Sunyer, F. X. (1990). Effect of the composition of the diet on energy intake. Nutrition Reviews 48, 94-105.

Pi-Sunyer, F. X., Hashim, S. A. \& Van Itallie, T. B. (1969). Insulin and ketone responses to ingestion of medium and long-chain triglycerides in man. Diabetes 18, 96-100.

Plomp, P. J. A. M., vanRoermund, C. W. T., Groen, A. K., Meijer, A. J. \& Tager, J. M. (1985). Mechanism of the stimulation of respiration by fatty acids in rat liver. FEBS Letters 193, 243-246.

Powley, T. L. \& Berthoud, H.-R. (1986). Participation of the vagus and other autonomic nerves in control of food intake. In Feeding Behavior, Neural and Humoral Control, pp. 67-102 [R. C. Ritter, S. Ritter and C. D. Barnes, editors]. Orlando: Academic Press.

Racotta, R. \& Russek, M. (1977). Food and water intake of rats after intraperitoneal and subcutaneous administration of glucose, glycerol and sodium lactate. Physiology and Behavior 18, 267-273.

Radziuk, J., McDonald, T. J., Rubenstein, D. \& Dupre, J. (1978). Initial splanchnic extraction of ingested glucose in normal man. Metabolism 27, 657-669.

Rawson, N. E., Blum, H., Osbakken, M. D. \& Friedman, M. I. (1994a). Hepatic phosphate trapping, decreased ATP, and increased feeding after 2,5-anhydro-D-mannitol. American Joumal of Physiology 266, R112-R117.

Rawson, N. E. \& Friedman, M. I. (1994). Phosphate loading prevents the decrease in ATP and increase in food intake produced by 2,5-anhydro-D-mannitol. American Journal of Physiology 266, R1792-R1796. 
Rawson, N. E., Ulrich, P. M. \& Friedman, M. I. (1994b). L-Ethionine, an amino acid analogue, stimulates eating in rats. American Journal of Physiology 267, R612-R615.

Ritter, R. C., Roelke, M. \& Neville, M. (1978). Glucoprivic feeding behavior in absence of other signs of glucoprivation. American Journal of Physiology 255, E617-E621.

Ritter, R. C. \& Slusser, P. G. (1980). Feeding and hyperglycemia induced by 5-thioglucose. American Journal of Physiology 238, E141-E144.

Ritter, R. C., Slusser, P. G. \& Stone, S. (1981). Glucoreceptors controlling feeding and blood glucose: Location in the hindbrain. Science 213, 451-453.

Ritter, S. \& Dinh, T. T. (1994). 2-Mercaptoacetate and 2-deoxy-D-glucose induce Fos-like immunoreactivity in rat brain. Brain Research 641, 111-120.

Ritter, S. \& Taylor, J. S. (1989). Capsaicin abolishes lipoprivic but not glucoprivic feeding in rats. American Journal of Physiology 256, R1232-R1239.

Ritter, S. \& Taylor, J. S. (1990). Vagal sensory neurons are required for lipoprivic but not glucoprivic feeding in rats. American Journal of Physiology 258, R1395-R1401.

Ritter, S., Taylor, J. S. \& Stone, S. (1988). Capsaicin-sensitive neurons mediate feeding induced by decreased fatty acid utilization but not by glucoprivation. Society for Neuroscience Abstracts 14, 532 .

Rogers, R. C., Kajrilas, P. J. \& Hermann, G. E. (1984). Projection of the hepatic branch of the splanchnic nerve to the brainstem of the rat. Journal of the Autonomic Nervous System 11, 223-225.

Rolls, B. J., Kimharris, S, , Fischman, M. W., Foltin, R. W., Moran, T. H. \& Stoner, S. A. (1994). Satiety after preloads with different amounts of fat and carbohydrate: implications for obesity. American Journal of Clinical Nutrition 60, 476-487.

Rossi, R., Geronimi, M., Gloor, P., Seebacher, C. \& Scharrer, E. (1995). Hyperpolarization of the cell membrane of mouse hepatocytes by fatty acid oxidation. Physiology and Behavior 57, 509--514.

Rumpler, W. V., Seale, J. L., Miles, C. W. \& Bodwell, C. E. (1991). Energy-intake restriction and diet-composition effects on energy expenditure in men. American Journal of Clinical Nutrition 53, 430-436.

Russek, M. (1963). An hypothesis on the participation of hepatic glucoreceptors in the control of food intake. Nature 197, 79-80.

Russek, M. (1970). Demonstration of the influence of an hepatic glucose-sensitive mechanism on food intake. Physiology and Behavior 5, 1207-1209.

Russek, M. (1981). Current status of the hepatostatic theory of food intake control. Appetite 2, 137-143.

Russek, M. \& Grinstein, S. (1974). Coding of metabolic information by hepatic glucoreceptors. In Neurohumoral Coding of Brain Function, pp. 81-97 [R. D. Myers and R. R. Drucker-Colin, editors]. New York: Plenum Publishing Corporation.

Russel, P. J. D. \& Mogenson, G. J. (1975). Drinking and feeding induced by jugular and portal infusions of 2-deoxy-D-glucose. American Journal of Physiology 229, 1014-1018.

Scharrer, E., DelPrete, E. \& Giger, R. (1993). Hepatic branch vagotomy enhances glucoprivic feeding in food-deprived old rats. Physiology and Behavior 54, 259-264.

Scharrer, E. \& Langhans, W. (1986). Control of food intake by fatty acid oxidation. American Journal of Physiology 250, R1003-R1006.

Scharrer, E. \& Langhans, W. (1990). Mechanisms for the effect of body fat on food intake. In Control of Body Fat Content, pp. 63-86 [J. M. Forbes and G. R. Hervey, editors]. London: Smith, Gordon and Company Ltd.

Scharrer, E., Thomas, D. W. \& Mayer, J. (1974). Absence of effect of intraaortal glucose infusion upon spontaneous meals of rats. Pflügers Archiv 351, 315-322.

Schmitt, M. (1973). Influences of hepatic portal receptors on hypothalamic feeding and satiety centers. American Journal of Physiology 225, 1089-1095.

Seifter, S. \& Englard, S. (1988). Energy metabolism. In The Liver: Biology and Pathobiology, pp. 279-315 [I. M. Arias, W. B. Jakoby, H. Popper, D. Schachter and D. A. Shafritz, editors]. New York: Raven Press.

Senn, M., Gross-Lüem, S. \& Langhans, W. (1995). Milchaufnahmeverhalten von Kälbern und metabolische Veränderungen als Antwort auf eine Milchmahlzeit (Milk drinking behaviour in calves and metabolic changes in response to a milk meal). Proceedings of the Society of Nutrition Physiology 4, 64.

Shimizu, N., Oomura, Y., Novin, D., Grijalva, C. V. \& Cooper, P. H. (1983). Functional correlations between lateral hypothalamic glucose-sensitive neurons and hepatic portal glucose-sensitive units in the rat. Brain Research 265, 49-54.

Shoemaker, W. C., Yanof, H. M., Turk, L. N. III \& Wilson, T. H. (1963). Glucose and fructose absorption in the unanesthetized dog. Gastroenterology 44, 654-663. 
Smith, G. P. \& Epstein, A. N. (1969). Increased feeding in response to decreased glucose utilization in rat and monkey. American Journal of Physiology 217, 1083-1087.

Stevens, H. C., Covey, T. R. \& Dills, W. L. Jr (1985). Inhibition of gluconeogenesis by 2,5-anhydro-Dmannitol in isolated rat hepatocytes. Biochimica et Biophysica Acta 845, 502-506.

Strubbe, J. H. \& Steffens, A. B. (1977). Blood glucose levels in portal and peripheral circulation and their relation to food intake in the rat. Physiology and Behavior 19, 303-307.

Stubbs, R. J. (1996). Dietary macronutrients and glucostatic control of feeding. Proceedings of the Nutrition Society 55, 467-483.

Surina, D. M., Langhans, W., Pauli, R. \& Wenk, C. (1993). Meal composition affects postprandial fatty acid oxidation. American Journal of Physiology 264, R1065-R1070.

Surina-Baumgartner, D., Arnold, M., Moses, A. \& Langhans, W. (1996). Metabolic effects of a fat and carbohydrate-rich meal in the rat. Physiology and Behavior (In the Press).

Thompson, D. A. \& Campbell, R. G. (1977). Hunger in humans induced by 2-deoxy-D-glucose: glucoprivic control of taste preference and food intake. Science 198, 1065-1068.

Tordoff, M. G. \& Friedman, M. I. (1986). Hepatic portal glucose infusions decrease food intake and increase food preference. American Journal of Physiology 251, R192-R196.

Tordoff, M. G. \& Friedman, M. I. (1988). Hepatic control of feeding: effect of glucose, fructose, and mannitol infusion. American Journal of Physiology 254, R969-R976.

Tordoff, M. G., Hopfenbeck, J. \& Novin, D. (1982). Hepatic vagotomy (partial hepatic denervation) does not alter ingestive responses to metabolic challenges. Physiology and Behovior 28, 417-424.

Tordoff, M. G., Rafka, R., DiNovi, M. J. \& Friedman, M. I. (1988). 2,5-Anhydro-D-mannitol: a fructose analogue that increases food intake in rats. American Journal of Physiology 254, R150-R153.

Tordoff, M. G., Rawson, N. \& Friedman, M. I. (1991). 2,5-Anhydro-D-mannitol acts in liver to initiate feeding. American Journal of Physiology 261, R283-R288.

Tordoff, M. G., Tluczek, J. P. \& Friedman, M. 1. (1989). Effect of hepatic portal glucose concentration on food intake and metabolism. American Journal of Physiology 257, R1474-R1480.

Torsdottir, I., Alpsten, M., Andersson, H., Schweizer, T. F., Tölli, J. \& Würsch, P. (1989). Gastric emptying and glycemic response after ingestion of mashed bean or potato flakes in composite meals. American Journal of Clinical Nutrition 50, 1415-1419.

Tremblay, A., Plourde, G., Despres, J.-P. \& Bouchard, C. (1989). Impact of dietary fat content and fat oxidation on energy intake in humans. American Journal of Clinical Nutrition 49, 799-805.

Van Es, A. J. H., Vogt, J. E., Niessen, C., Veth, J., Rodenburg, L., Teeuwse, V., Dhuyvetter, J., Deurenberg, P., Hautvast, J. G. A. J. \& Van der Beek, E. (1984). Human energy metabolism below, near and above energy equilibrium. British Journal of Nutrition 52, 429-442.

Van Itallie, T. B. \& Kissileff, H. R. (1983). The physiological control of energy intake: an econometric perspective. American Journal of Clinical Nutrition 38, 978-988.

Verboeket-van de Venne, W. P. H. G., Westerterp, K. R. \& ten Hoor, F. (1994). Substrate utilization in man: effects of dietary fat and carbohydrate. Metabolism 43, 152-156.

Walls, E. K. \& Koopmans, H. S. (1989). Effect of intravenous nutrient infusions on food intake in rats. Physiology and Behavior 45, 1223-1226.

Walls, E. K., Willing, A. E. \& Koopmans, H. S. (1991). Intravenous nutrient-induced satiety depends on feeding-related gut signals. American Journal of Physiology 261, R313-R322.

Woods, S. C., Stein, L. J., McKay, L. D. \& Porte, D. Jr (1984). Suppression of food intake by intravenous nutrients and insulin in the baboon. American Journal of Physiology 247, R393-R401.

Yang, Z. J., Ratto, C., Gleason, J. R., Bellantone, R., Crucitti, F. \& Meguid, M. M. (1992). Influence of anterior subdiaphragmatic vagotomy and TPN on rat feeding behavior. Physiology and Behavior 51, 919-926.

Yin, T. H., Tsai, W. H., Barone, F. C. \& Wayner, M. J. (1979). Effects of continuous intramesenteric infusion of glucose and amino acids on food intake of rats. Physiology and Behavior 22, 1207-1210. 